This item was submitted to Loughborough's Institutional Repository (https://dspace.lboro.ac.uk/) by the author and is made available under the following Creative Commons Licence conditions.

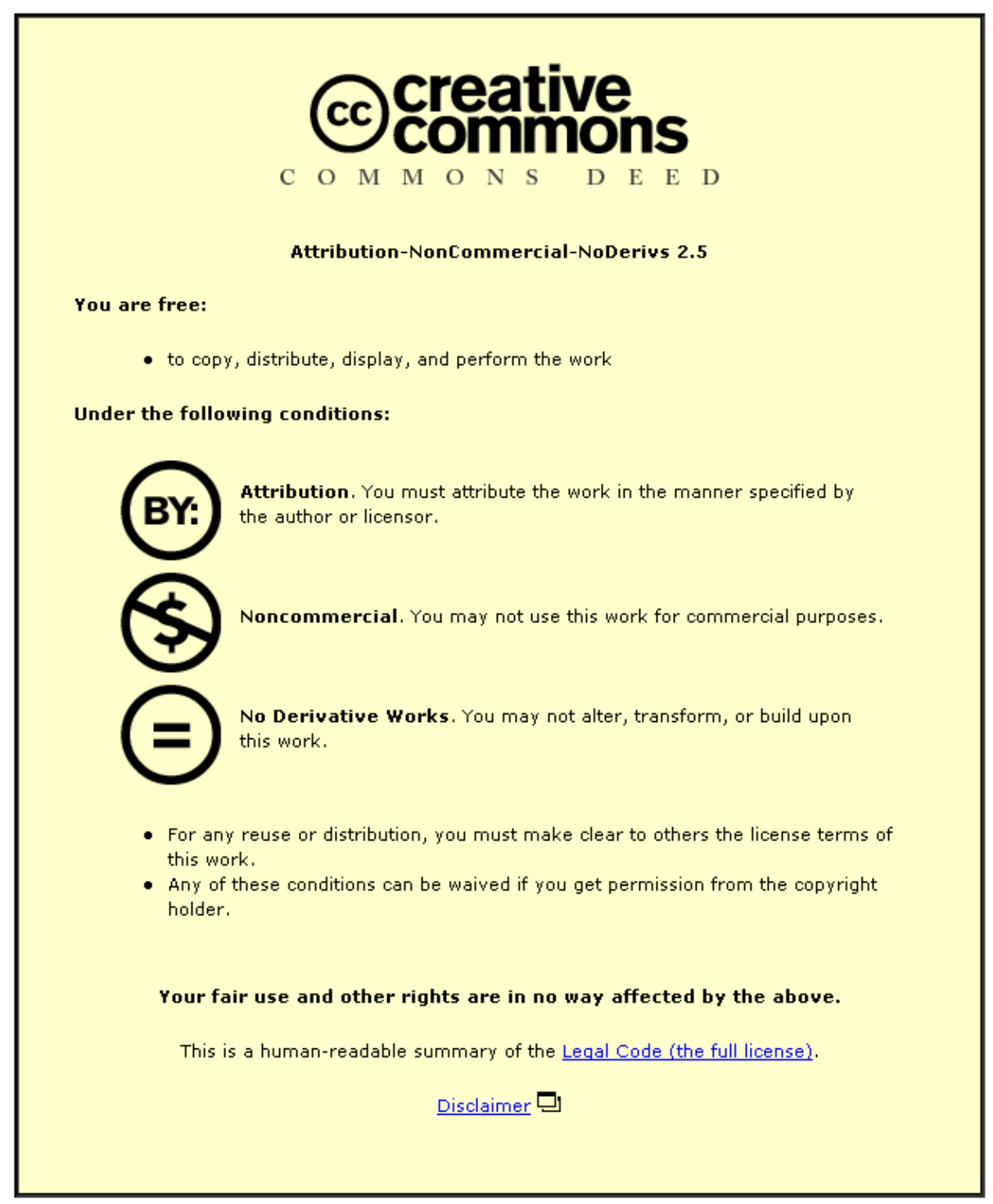

For the full text of this licence, please go to: http://creativecommons.org/licenses/by-nc-nd/2.5/ 


\title{
Elastohydrodynamic solution for concentrated elliptical point contact of machine elements under combined entraining and squeeze-film motion
}

\author{
D Jalali-Vahid, H Rahnejat and Z M Jin \\ Department of Mechanical and Manufacturing Engineering, University of Bradford
}

\begin{abstract}
This paper presents numerical solution of isothermal elastohydrodynamic conjunction for concentrated contact of elastic bodies under the elliptical point contact condition. The solution includes the effect of squeeze-film motion that occurs under transient conditions due to the application of cyclic loads and/or oscillating motions in machine elements. It is shown that this time-dependent behaviour increases the load-carrying capacity of the contact which is largely responsible as a mechanism of lubricant film formation when the low speeds of entraining motion yield a low film thickness. An extrapolated oil-film thickness formula is also presented that can be employed under dynamic conditions.
\end{abstract}

Keywords: concentrated elliptical point contact, elastohydrodynamic lubrication, squeeze-film action

\section{NOTATION \\ a semimajor axis of the contact ellipse in the transverse direction \\ $b \quad$ semiminor axis of the contact ellipse in the entraining direction \\ $A, B, C, N, L, M$ \\ relaxation coefficients \\ $\bar{c} \quad$ number of divisions in the semimajor axis \\ $\bar{d} \quad$ number of divisions in the semiminor axis \\ $E \quad$ modulus of elasticity \\ $E^{\prime} \quad$ equivalent Young's modulus \\ $G^{*}$ \\ $h$ \\ $\frac{h}{h}$ \\ $H_{0}$ \\ $\mathrm{d} h / \mathrm{d} t$ \\ $l \quad$ constant used to determine the length of the \\ side leakage region \\ $m \quad$ constant used to determine the length of the inlet region \\ $n \quad$ constant used to determine the length of the outlet region \\ $P \quad$ pressure \\ $\bar{P} \quad$ dimensionless pressure}

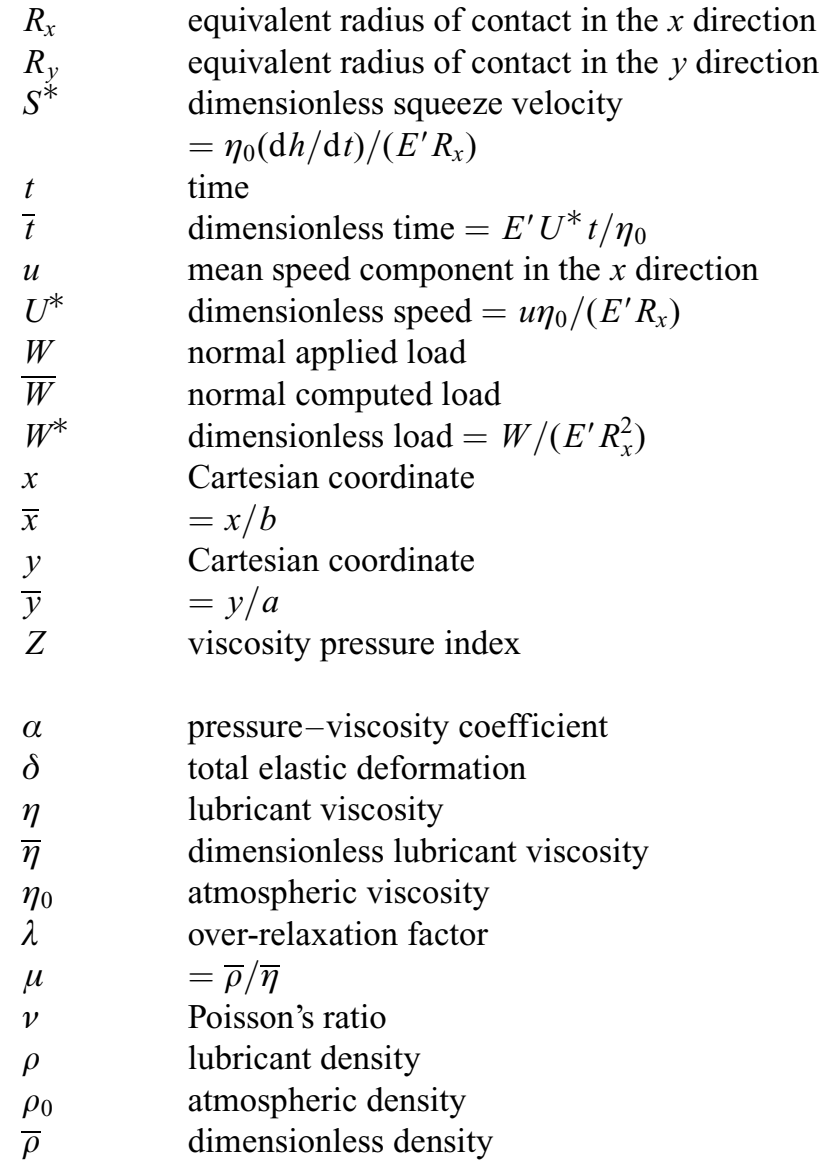




\section{INTRODUCTION}

Point contact elastohydrodynamic lubrication (EHL) conditions occur in the counterformal contact of many machine elements such as balls to races contacts. Throughout the past three decades there have been various solutions for these conditions reported in the literature. These include the initial solution surmised by Grubin [1] which has since been confirmed both experimentally [2-4] and by numerical solutions of pressure distributions and the corresponding film shapes [5-10]. Important features of these observations and the corresponding numerical solutions are the flat film shape in the Hertzian region and the conformity of the pressure profile to the elastostatic Hertzian pressure profile. The occurrence of the dip in the film thickness at the exit constriction and the corresponding secondary pressure spike in this region have been widely investigated, particularly because of the significant effect that the pressure spike has on the subsurface stress field and the fatigue life of rolling and sliding members $[11,12]$.

Another less attempted problem in the contact of machine elements is the application of periodic normal loads or motions that occur as the result of vibrations or chatter. These sources of excitation give rise to the normal approach or separation of contacting elastic bodies which in turn induce a squeeze action upon the lubricant film. Some of the published works include the effect of squeezefilm action on the pressure distribution and the lubricant film thickness. In 1962, Christensen [13] provided the first numerical solution to the problem of pure squeeze under the line contact EHL condition. A point contact EHL solution for pure normal motion was later presented by Christensen [14] in 1970. A subsequent pure squeeze solution for materials of low elastic modulus under the isoviscous point contact condition was presented by Herrebrugh [15] in 1970.

Experimental investigation of an impacting ball on a plane, leading to the pure squeeze EHL point contact condition has been carried out by Dowson and Jones [16] in 1967-8, Paul and Cameron [17] in 1972, and Safa and Gohar [18] in 1986. Numerical solutions for combined squeeze and entraining motion under the EHL condition have been reported by various researchers, including Bedewi et al. [19], and Lee and Hamrock [20] for line contact conditions, Mostofi and Gohar [21] for the point contact condition, and Rahnejat [22] for the finite line contact condition. A feature of all these solutions has been the inclusion of a constant squeeze-film velocity in the normal approach of contiguous bodies. This leads to an approximation for the dynamic behaviour of the lubricated contact under cyclic loads.

However, in order to simulate the non-steady state effects in lubricated contacts (as in the case of an impacting ball in references [16-18]) a dynamic solution of the EHL problem is required. Such solutions have recently been reported by Dowson and Wang [23] for the impact of a ball on a lubricated layer under the pure squeeze condition, and by Wijnant and Venner [24] for the impact of a ball under a combined entraining and squeeze-film motion. The former observed a nearly constant film thickness during the impact as well as the very modest contribution of viscous damping during the entire dynamic process. Significantly, the normal approach-depart velocity was found to be considerably lower than the initial velocity of the impact, and the pressure distribution closely conforms to the steady state EHL conjunction under the pure squeeze condition, a feature that has been observed experimentally by Safa and Gohar [18]. The deviation of their non-steady state solution from that of a steady state solution has been the occurrence of an unusually high pressure spike at the outset of ball impact. Wijnant and Venner [24] have also shown that, for the case where the entraining speeds of contacting bodies are much larger than the squeeze velocity, the non-steady state problem reduces to the solution of steady state EHL. However, for larger impacting velocities the steady and non-steady state solutions may diverge.

Other solutions, incorporating the squeeze-film action have been undertaken for specific applications, such as for a piston ring by Dowson et al. [25], who incorporated the inertial effect under dynamic conditions. They observed that for most of the piston cycle the effect of the squeezefilm action was insignificant. Other solutions for a camfollower under the line contact condition have been reported by Matthews and Sadeghi [26], Dowson et al. [27] and Mei and Xie [28].

While the non-steady state solutions of the EHL problem are desired, e.g. for dynamics of rolling element to races contacts under oscillating conditions, the solution is often quite time intensive. Furthermore, for low squeeze-roll speed ratios and small load perturbations which are typical of many bearing applications a steady state solution with a low value of representative squeeze velocity should suffice. Typical values of squeeze velocity in many EHL applications are of the order of thousandths to hundredths of the speed of entraining motion, as indicated in reference [23] as well as by the experimental evidence of nearly steady state pressure traces in references [17] and [18]. Therefore, there exists a subclass of EHL problems at low squeeze-roll speed ratios and low fluctuating contact loads where steady state EHL or rolling and squeeze-film motion approximates the non-steady state solution very closely. This has been corroborated by numerical solution of a wavy surfaced disc EHL problem, obtaining the instantaneous lubricant reaction from an extrapolated oil-film equation in steps of time by Mehdigoli et al. [29], the results of which conform very closely with the experimental work of Dareing and Johnson [30]. The fact that this has been shown to be the case forms the basis for this paper which presents the EHL of elliptical contacts under combined entraining and squeeze-film action at low squeeze velocities and low to moderate loads. A new lubricant film thickness regression formula is also presented that includes the effect of squeeze-film action. 


\section{THEORETICAL FORMULATION}

The following governing equations are employed for solution of the problem of rolling and normally approaching an elastohydrodynamic point contact:

\subsection{The Reynolds equation}

The general Reynolds equation for EHL of point contacts with entraining motion in the $x$ direction in dimensionless form is written as

$$
\begin{aligned}
\frac{\partial}{\partial x}\left(\frac{\rho h^{3}}{\eta} \frac{\partial P}{\partial x}\right) & +\frac{\partial}{\partial y}\left(\frac{\rho h^{3}}{\eta} \frac{\partial P}{\partial y}\right) \\
& =12\left[u \frac{\partial(\rho h)}{\partial x}+\frac{\partial(\rho h)}{\partial t}\right]
\end{aligned}
$$

where the following dimensionless groups apply:

$$
\begin{aligned}
& \bar{x}=\frac{x}{b}, \quad \bar{y}=\frac{y}{a}, \quad \bar{\rho}=\rho / \rho_{0}, \quad \bar{\eta}=\frac{\eta}{\eta_{0}} \\
& \bar{h}=\frac{h}{R_{x}}, \quad \bar{P}=\frac{P}{E^{\prime}}, \quad U^{*}=\frac{u \eta_{0}}{R_{x} E^{\prime}} \\
& \bar{t}=E^{\prime} U^{*} t / \eta_{0}
\end{aligned}
$$

For the purpose of discretization the following parameter is defined:

$$
\phi=\bar{P} h^{3 / 2}
$$

Rearranging the Reynolds equation in terms of the above parameter gives

$$
\begin{array}{r}
\frac{\partial}{\partial \bar{x}}\left(\bar{\mu} \bar{h}^{3 / 2} \frac{\partial \phi}{\partial \bar{x}}-\frac{3}{2} \bar{\mu} \bar{h}^{1 / 2} \phi \frac{\partial \bar{h}}{\partial \bar{x}}\right) \\
+\frac{1}{K^{2}} \frac{\partial}{\partial \bar{y}}\left(\bar{\mu} \bar{h}^{3 / 2} \frac{\partial \phi}{\partial \bar{y}}-\frac{3}{2} \bar{\mu} \bar{h}^{1 / 2} \phi \frac{\partial \bar{h}}{\partial \bar{y}}\right) \\
=\frac{12 U^{*} b}{R_{x}}\left[\frac{\partial(\bar{\rho} \bar{h})}{\partial \bar{x}}+\frac{b \bar{\rho}}{R_{x}} \frac{\partial \bar{h}}{\partial \bar{t}}\right]
\end{array}
$$

It should be noted that $\bar{\rho}$ is assumed to remain constant with time. The implication of this assumption is that an approximate steady state solution with an average squeeze velocity is obtained (rather than an instantaneous value for squeeze velocity that would normally be calculated in a non-steady state dynamic solution). For low values of squeeze velocity, as is the case for all the solutions presented here, the error in assuming constant $\bar{\rho}$ with time is likely to be quite small. The solution nevertheless can only be considered as approximate.

\subsection{Lubricant density-pressure dependence}

The density-pressure relationship used is taken from Dowson and Higginson [5], in dimensionless form as

$$
\bar{\rho}=1+\frac{\varepsilon \bar{P} E^{\prime}}{1+\xi \bar{P} E^{\prime}}
$$

where $\varepsilon$ and $\xi$ are constants related to the type of lubricant employed.

\subsection{Lubricant viscosity-pressure relationship}

Roelands [31] viscosity-pressure relationship is taken in dimensionless form as

$$
\bar{\eta}=\left(\frac{\eta_{\infty}}{\eta_{0}}\right)^{1-\left(1+\bar{P} E^{\prime} / \gamma\right)^{Z}}
$$

where $Z$ is the viscosity pressure index, $\eta_{\infty}=$ $0.631 \times 10^{-4} \mathrm{Pas}$ and $\gamma=1.9609 \times 10^{8} \mathrm{~N} / \mathrm{m}^{2}$.

\subsection{The elastic film shape}

The film shape in the dimensionless form is of the same form as that proposed in references [32-35]:

$$
\bar{h}(\bar{x}, \bar{y})=H_{0}+\frac{b^{2}(\bar{x}-m)^{2}}{2 R_{x}^{2}}+\frac{a^{2}(\bar{y}-l)^{2}}{2 R_{x} R_{y}}+\frac{\delta(\bar{x}, \bar{y})}{R_{x}}
$$

where $H_{0}$ is the central film thickness and $\delta(x, y)$ is the dimensionless elastic deflection of the contiguous contacting bodies.

\subsection{The elasticity equation}

When the bodies in contact are treated as elastic halfspaces, a relationship for $\delta(x, y)$ is obtained using the following force-displacement relationship:

$$
\delta=\frac{2 P}{\pi} \int_{-\bar{a}}^{\bar{a}} \int_{-\bar{b}}^{\bar{b}} \frac{\mathrm{d} \bar{x}_{1} \mathrm{~d} \bar{y}_{1}}{\left[\left(\bar{y}-\bar{y}_{1}\right)^{2}+\left(\bar{x}-\bar{x}_{1}\right)^{2}\right]^{1 / 2}}
$$

The above equation can be solved analytically for a constant pressure acting over an element. This will yield a set of influence coefficients that enable the evaluation of contact deflections by the superposition principle as

$$
\delta_{I, J}(\bar{x}, \bar{y})=\frac{2}{\pi} \sum_{j=1,2, \ldots}^{2 l \bar{c}} \sum_{i=1,2, \ldots}^{(m+n) \bar{d}} P_{i, j} D_{i^{*}, j^{*}}
$$

where according to Johnson [36]

$$
\begin{aligned}
& \bar{c}=\text { number of divisions in the semimajor axis } \\
& n=\text { constant used to determine the length of the outlet } \\
& \quad \text { region } \\
& \bar{d}=\text { number of divisions in the semiminor axis }
\end{aligned}
$$




$$
\begin{aligned}
& i^{*}=|I-i|+1 \\
& j^{*}=|J-j|+1 \\
& D=b\left(\bar{x}+\frac{1}{2 \bar{d}}\right) \\
& \times \ln \left\{\frac{K\left(\bar{y}+\frac{1}{2 \bar{c}}\right)+\left[K^{2}\left(\bar{y}+\frac{1}{2 \bar{c}}\right)^{2}+\left(\bar{x}+\frac{1}{2 \bar{d}}\right)^{2}\right]^{1 / 2}}{K\left(\bar{y}-\frac{1}{2 \bar{c}}\right)+\left[K^{2}\left(\bar{y}-\frac{1}{2 \bar{c}}\right)^{2}+\left(\bar{x}+\frac{1}{2 \bar{d}}\right)^{2}\right]^{1 / 2}}\right\} \\
& +a\left(\bar{y}+\frac{1}{2 \bar{c}}\right) \\
& \times \ln \left\{\frac{\left(\bar{x}+\frac{1}{2 \bar{d}}\right)+\left[K^{2}\left(\bar{y}+\frac{1}{2 \bar{c}}\right)^{2}+\left(\bar{x}+\frac{1}{2 \bar{d}}\right)^{2}\right]^{1 / 2}}{\left(\bar{x}-\frac{1}{2 \bar{d}}\right)+\left[K^{2}\left(\bar{y}+\frac{1}{2 \bar{c}}\right)^{2}+\left(\bar{x}-\frac{1}{2 \bar{d}}\right)^{2}\right]^{1 / 2}}\right\} \\
& +b\left(\bar{x}-\frac{1}{2 \bar{d}}\right) \\
& \times \ln \left\{\frac{K\left(\bar{y}-\frac{1}{2 \bar{c}}\right)+\left[K^{2}\left(\bar{y}-\frac{1}{2 \bar{c}}\right)^{2}+\left(\bar{x}-\frac{1}{2 \bar{d}}\right)^{2}\right]^{1 / 2}}{K\left(\bar{y}+\frac{1}{2 \bar{c}}\right)+\left[K^{2}\left(\bar{y}+\frac{1}{2 \bar{c}}\right)^{2}+\left(\bar{x}-\frac{1}{2 \bar{d}}\right)^{2}\right]^{1 / 2}}\right\} \\
& +a\left(\bar{y}+\frac{1}{2 \bar{c}}\right) \\
& \times \ln \left\{\frac{\left(\bar{x}-\frac{1}{2 \bar{d}}\right)+\left[K^{2}\left(\bar{y}-\frac{1}{2 \bar{c}}\right)^{2}+\left(\bar{x}-\frac{1}{2 \bar{d}}\right)^{2}\right]^{1 / 2}}{\left(\bar{x}+\frac{1}{2 \bar{d}}\right)+\left[K^{2}\left(\bar{y}-\frac{1}{2 \bar{c}}\right)^{2}+\left(\bar{x}+\frac{1}{2 \bar{d}}\right)^{2}\right]^{1 / 2}}\right\}
\end{aligned}
$$

\section{THE NUMERICAL SOLUTION}

\subsection{The solution procedure}

The solution procedure is highlighted by the computational flow diagram in Fig. 1. To solve the EHL of a point contact under combined rolling and squeeze-film motion the Reynolds equation, the elastic film shape and the lubricant state equations described are solved simultaneously by employing the following procedure:

1. For a chosen applied load and geometry, the footprint dimensions $a$ and $b$ of the Hertzian elastostatic dry contact and the corresponding elliptical parameter $K$ are first obtained.

2. The Hertzian dry contact pressure distribution is used as an initial guess for the solution of the lubricant state equations, and also for the solution of the Reynolds equation by Gauss-Seidel iterations. The method of solution is based upon the central difference scheme approximation of a rectangular two-direction regular grid of 67 in the direction of entraining motion with 17 elements in the lateral direction. Owing to the symmetric nature of the problem in the transverse direction to that of the entraining motion, it is only necessary to undertake the solution for half the contact domain.

The solution methodology utilizes a forward iteration procedure from an initially assumed pressure distribution (i.e. the elastostatic Hertzian pressure distribution). This enables the calculation of the corresponding elastic deformation of the semi-infinite solids to be carried out. The subsequent solution of the Reynolds equation provides the hydrodynamic pressure distribution. This iterative process continues in order to obtain the converged pressure distribution, the film shape for a given load and other given operating conditions such as the speed of entraining motion. The solution requires the use of an over-relaxation factor for rapid convergence of the innermost loop (loop I) and an under-relaxation factor for convergence of the pressure and load loops (loops I and II). The convergence criterion requires the sum difference of successive pressure distributions to be within 10 per cent of the sum of the calculated pressure distribution. The computation time on a Pentium pro $200 \mathrm{MHz}$ is approximately $0.5-5 \mathrm{~h}$, depending upon the operating condition.

\subsection{Solution for $\phi$}

Equation (5) is discretized in terms of $\phi$ using the standard central difference scheme as follows:

$$
\begin{aligned}
\phi_{i, j, n+1} & =\phi_{i, j, n} \\
& \lambda\left(M_{i, j}-A_{i, j} \phi_{i+1, j, n}-B_{i, j} \phi_{i, j-1, n+1}-\right. \\
- & \frac{\left.C_{i, j} \phi_{i-1, j, n+1}-D_{i, j} \phi_{i, j+1, n}+L_{i, j} \phi_{i, j, n}\right)}{L_{i, j}}
\end{aligned}
$$

where $\lambda$ is an overrelaxation factor used to speed up the process of convergence, and other terms are provided in the Appendix.

The pressure elements are calculated, using equation (4), where the dimensionless central film thickness is obtained using the following relations:

$$
\left(H_{0}\right)_{\text {new }}=\left(H_{0}\right)_{\text {old }}\left(\frac{W}{\bar{W}}\right)^{c}
$$




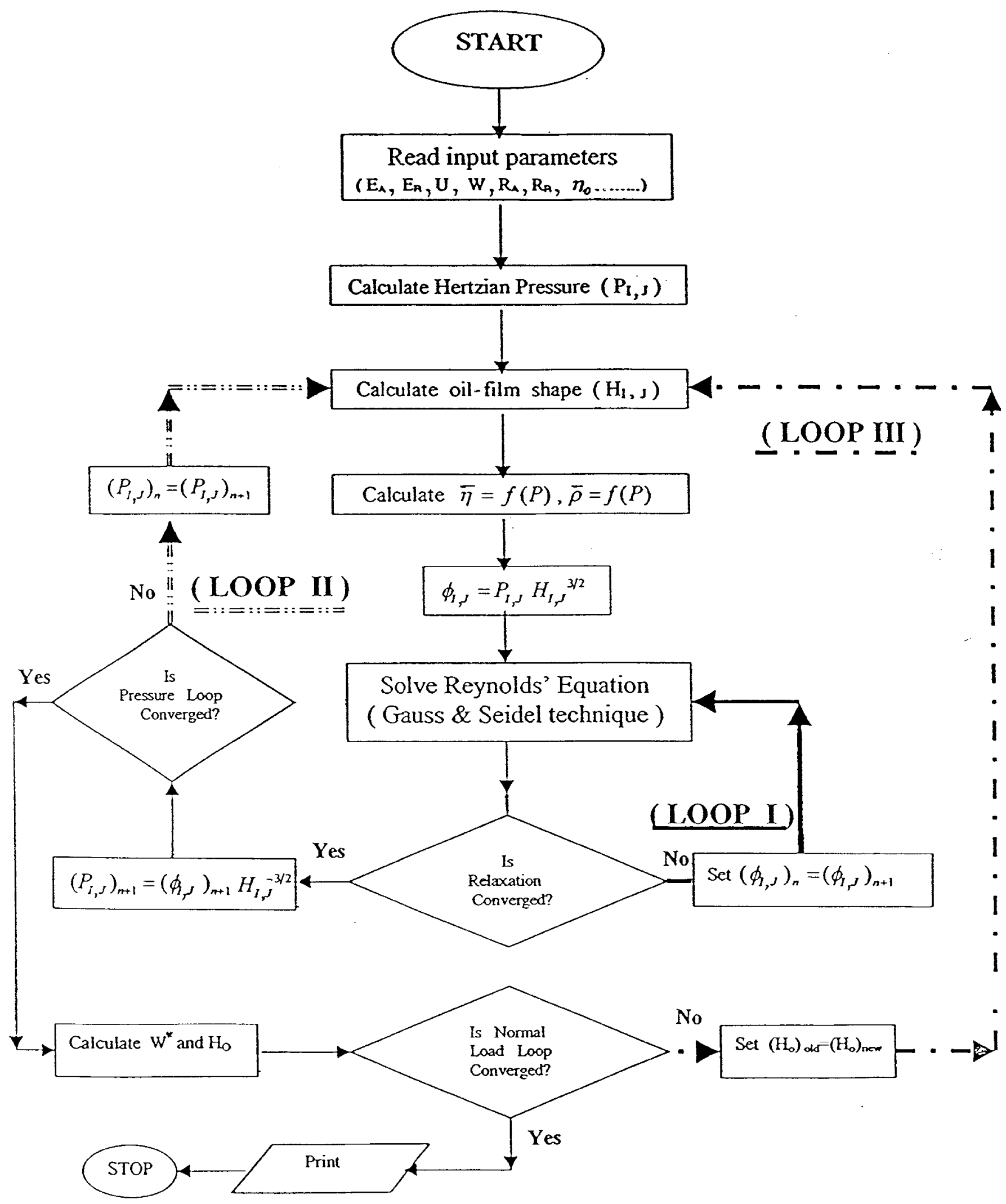

Fig. 1 Flow diagram of computational procedures 
where $c$ is a factor which is dependent on $W . W$ and $\bar{W}$ are the applied and calculated contact loads respectively, with the latter given by the instantaneous integrated pressure distribution over the contact domain as

$$
\bar{W}=E^{\prime} a b \int_{0}^{m+n} \int_{0}^{2 l} P \mathrm{~d} \bar{x} \mathrm{~d} \bar{y}
$$

\section{RESULTS AND DISCUSSION}

There are five main parameters that govern the pressure distribution and film shape in the elastohydrodynamic point contact condition. These are the load parameter $W^{*}$, speed parameter $U^{*}$, materials parameter $G^{*}$, normal approach parameter $S^{*}$ and contact ellipticity ratio $K$. The effects of these parameters on the pressure distribution and the corresponding film thickness are described in this paper.

Figures $2 \mathrm{a}$ and $\mathrm{b}$ depict the results obtained for pressure distribution and film thickness variation with an increasing magnitude of the normal approach parameter (i.e. an increasing squeeze velocity), and with other governing parameters remaining constant. With increasing squeeze velocity the load carrying capacity increases. When the load parameter is kept constant, the resulting effect is an increase in the magnitude of the pressure spike and a corresponding increase in the minimum exit film. This trend is also observed in the numerical solutions of Mostofi and Gohar [21] for elliptical point contacts and Rahnejat [22] for finite line contacts. An important feature of the pressure distribution at higher values of the normal approach parameter is the 'convergence' of the primary and secondary pressure peaks, resulting in a pressure spike considerably in excess of the maximum Hertzian pressure. The implication of this is an increasing chance of induced subsurface fatigue failure, discussed in some detail by Houpert et al. [11] and in a recent paper by Johns-Rahnejat and Gohar [37]. As the squeeze velocity increases, the accuracy of the steady state solution with a constant (an average) value for squeeze velocity decreases as opposed to a non-steady state solution, incorporating the instantaneous squeeze velocity. Therefore, the pressure profile with the highest squeeze velocity at $S^{*}=-8.41 \times 10^{-16}$ (corresponding to $-0.05 \mathrm{~mm} / \mathrm{s}$ ) tend to have a larger degree of inaccuracy at the same speed of entraining motion. This has been reported by Wijnant and Venner [24].

Figures $3 \mathrm{a}$ and $\mathrm{b}$ show three-dimensional pressure distributions corresponding to the two-dimensional pressure profiles of Fig. 2a for the cases of pure entraining motion and $S^{*}=-2.52 \times 10^{-16}$ (a squeeze velocity of $0.015 \mathrm{~mm} / \mathrm{s}$ ). The corresponding lubricant film shapes are shown in Fig. 3b. It can be observed that the minimum film occurs at the trailing edge of the contact under pure entraining motion and tends towards the side constriction as a normal approach is introduced. This is more clearly shown in Fig. 4, where the contour in Fig. 4a represents pure entraining motion and that in Fig. $4 \mathrm{~b}$ illustrates the combined entraining and squeeze-film action.

Good agreement is obtained between the results presented in this paper and those reported by Hamrock and Dowson [34] and Chittenden et al. [38] under the same pure entraining conditions (Fig. 5). The lines in this figure are obtained using the oil-film extrapolated equations of references [34] and [38]. The points plotted in the figure show the numerical results obtained in the current analysis. All these solutions are mainly lightly loaded contacts. In the case of this paper the solutions are in the region $\alpha P_{0}=$ 4-8 which puts them in the same region in the Greenwood [39] clearance charts as those of Hamrock and Dowson [34].

It can be observed that the numerical results obtained here fall in between the findings of reference [34] and those of reference [38] for the cases of pure entraining motion. In this paper, note should be taken of the increase in the value of the minimum film thickness when a normal approach velocity is included, at the same value of load. This increases the contact load-carrying capacity, with all other conditions remaining constant. The same trend is also observed in references [21] and [22]. The extrapolated equation (14), including the effect of squeeze, is also plotted to show the degree of conformity with the actual numerical results.

In the contact of many machine elements the squeezefilm motion contributes significantly in the formation of a coherent film as corroborated by these results. Such conditions contribute to absence of wear, e.g. in camfollower contacts, as reported by Hamilton [40]. The squeeze-film action is also a very useful mechanism at the start-up in many machine elements.

Table 1 shows a list of results for film thickness obtained under various conditions. The numerical solution results $\bar{h}_{\text {min }}$ are listed in the eighth column, with the $\tilde{H}_{\text {min }}$ values from the current regression formula indicated in the ninth column. The values are clearly very close, indicating that a close fit has been achieved. The tenth column lists the minimum film thickness values $\hat{H}_{\text {min }}$ under the same conditions, using the regression formula of Hamrock and Dowson [34]. The last column shows the percentage error between the values obtained in the ninth and tenth columns. The current regression formula includes the effect of squeeze. The same ranges of values have been employed for the variations in the governing load, speed, material and ellipticity parameters as those in reference [34]. A similar range for squeeze velocity is employed as that in reference [21]. There are 50 simulation run results in the table which are mostly employed to obtain a regression formula for the lubricant film thickness at the position of minimum exit as

$$
\begin{aligned}
\bar{h}_{\min }= & 2.55\left(G^{*}\right)^{0.476}\left(W^{*}\right)^{-0.062}\left(U^{*}\right)^{0.658} \\
& \times\left(-22.2 \times 10^{14} S^{*}+1\right)\left(1-\mathrm{e}^{-0.675 K}\right)
\end{aligned}
$$




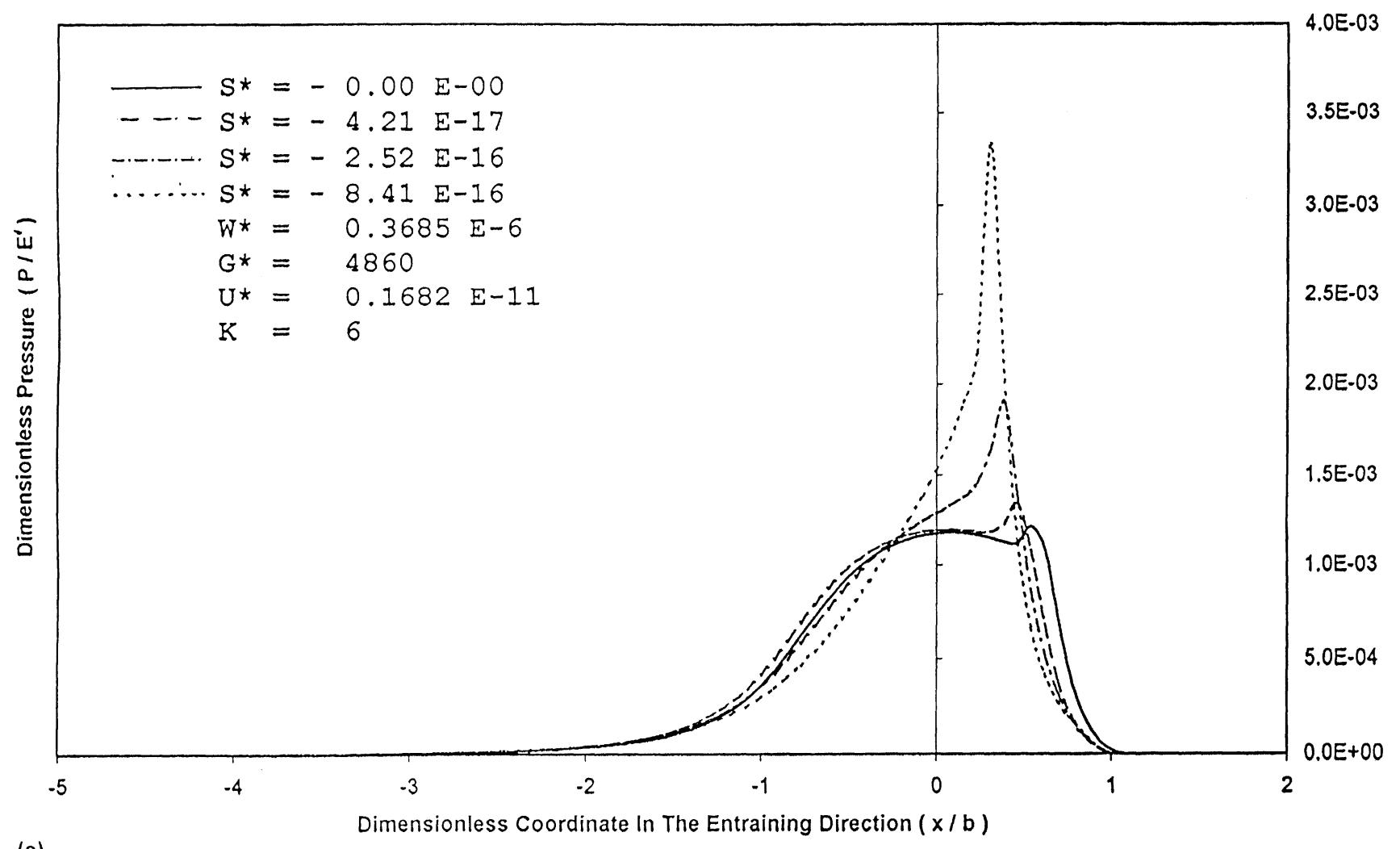

(a)

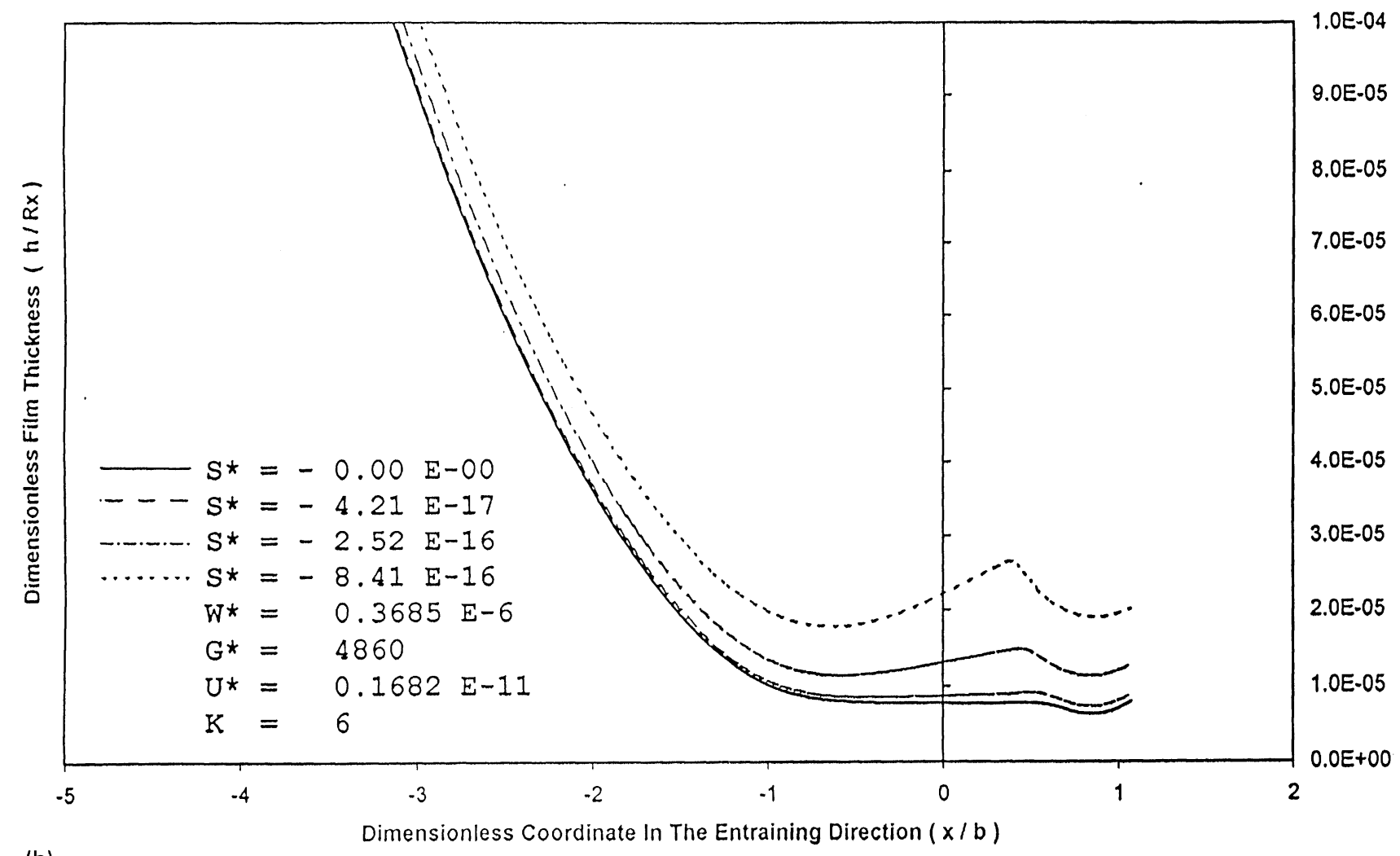

(b)

Fig. 2 (a) Pressure distribution for different squeeze velocities. (b) Film thickness profiles for different squeeze velocities 


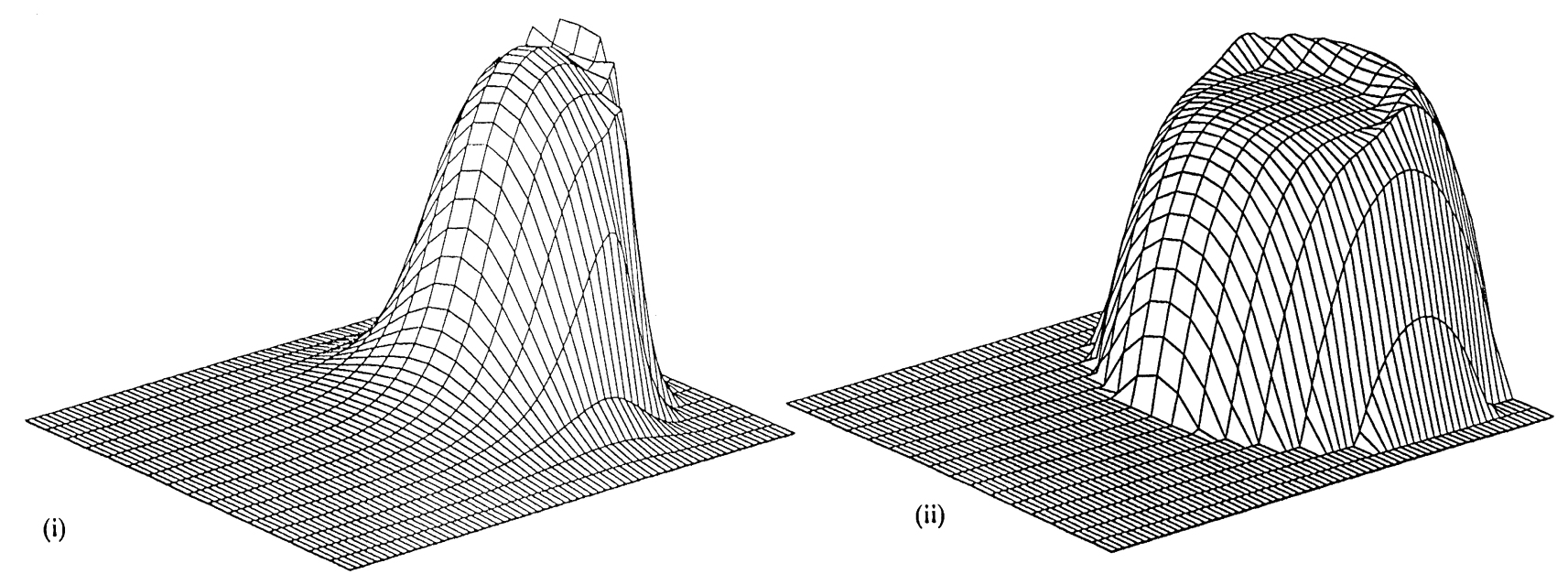

(a)

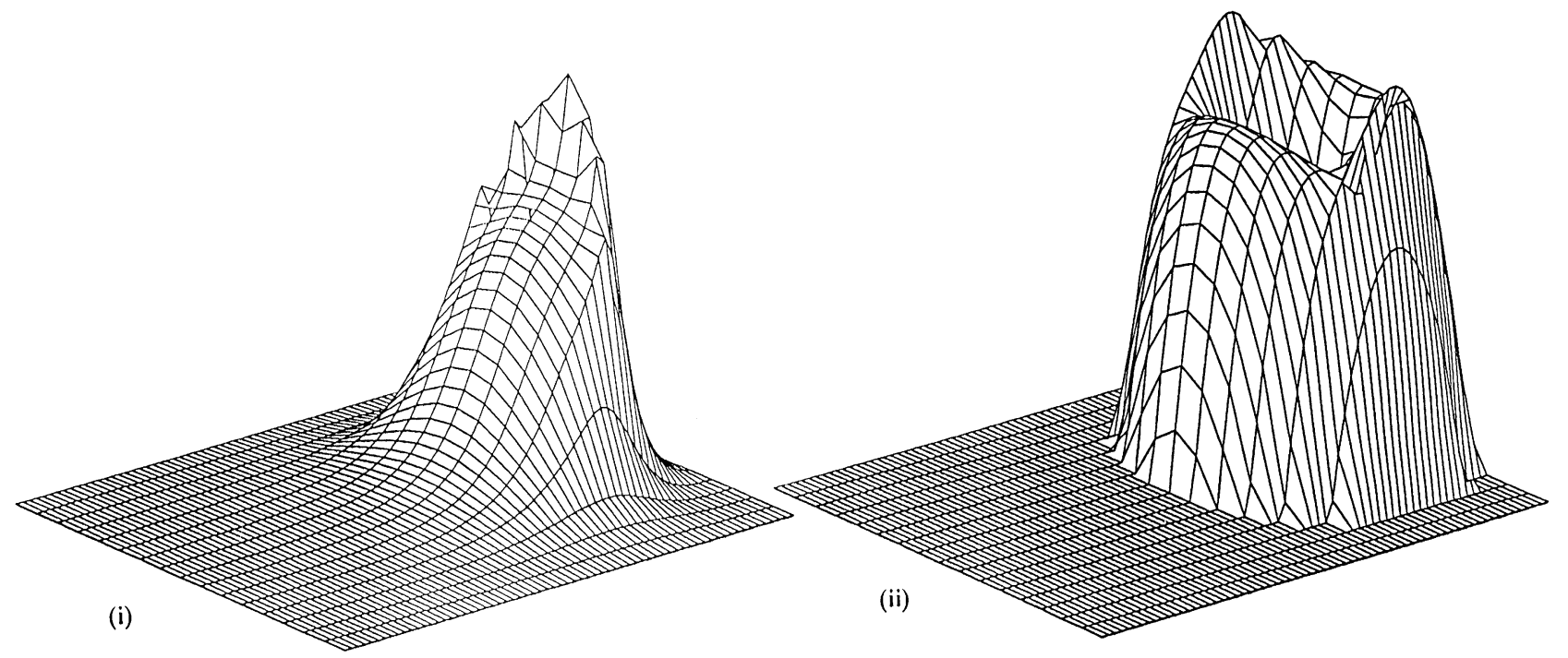

(b)

Fig. 3 (a) Three-dimensional pressure distribution and film shape for pure rolling (relating to Figs 2a and b: (i) pressure distribution, (ii) film shape). (b) Three-dimensional pressure distribution and film shape for combined rolling and squeeze action $\left(S^{*}=-2.52 \times 10^{-16}\right.$ ) (relating to Figs $2 \mathrm{a}$ and b): (i) pressure distribution, (ii) film shape)
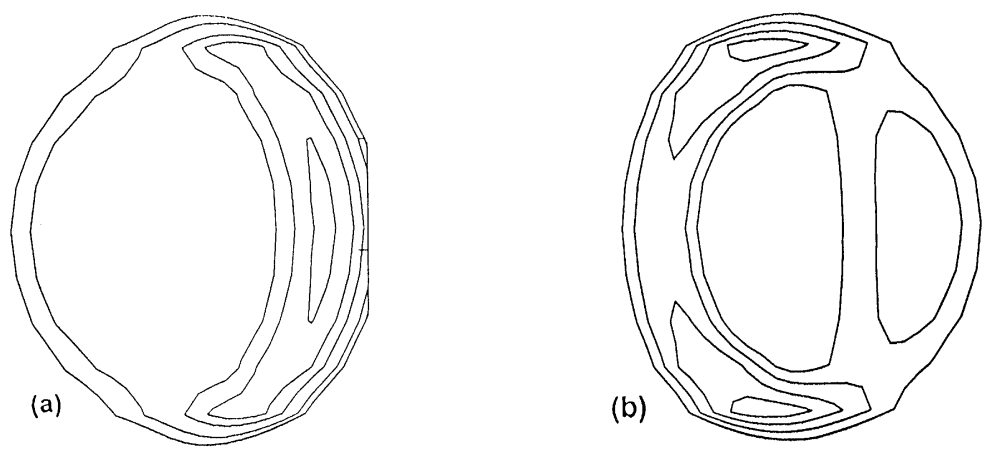

Fig. 4 Two-dimensional oil-film contours (relating to the three-dimensional plot in Fig. 3): (a) pure entraining motion; (b) combined entraining and squeeze motion $\left(S^{*}=-2.52 \times 10^{-16}\right)$. (Note that $K=6$; the figure is stretched in the direction of entraining motion for presentation) 


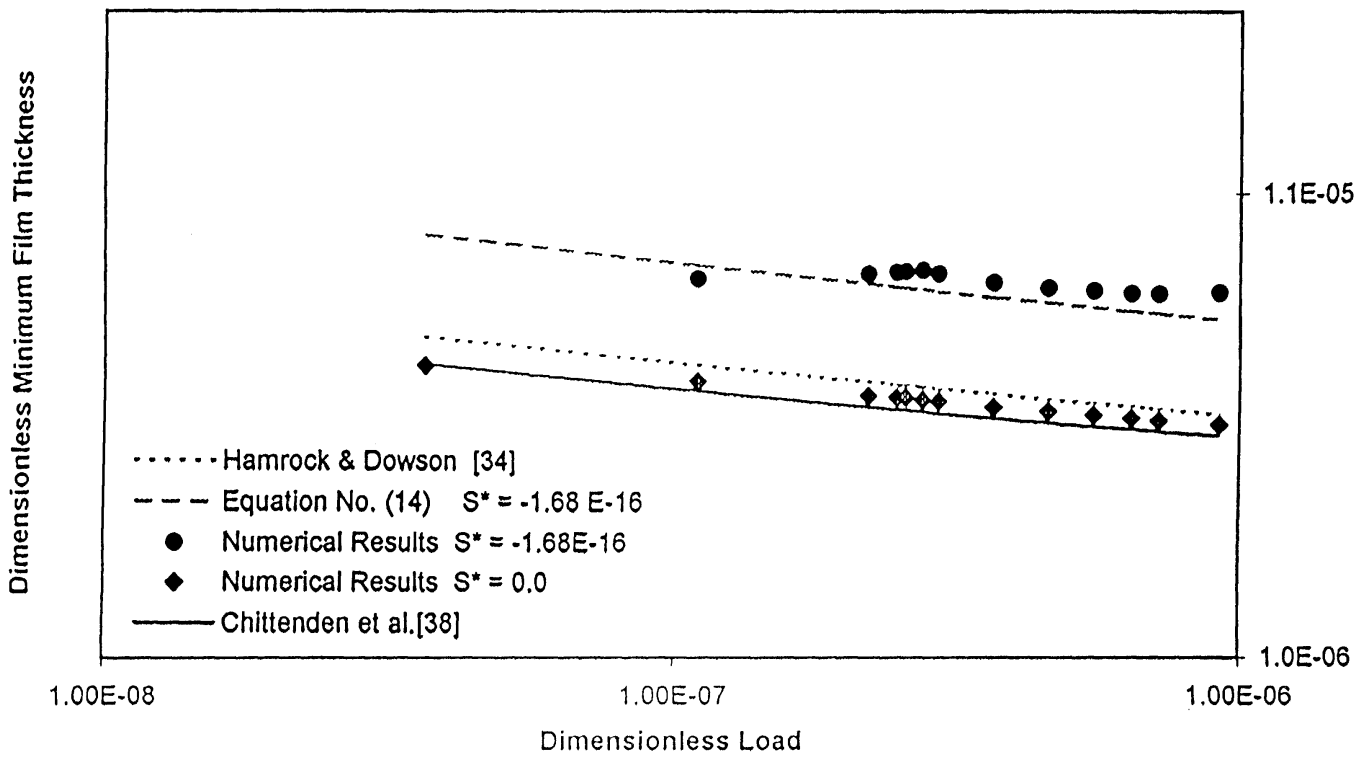

Fig. 5 Variation in the minimum film thickness with load $\left(U^{*}=1.682 \times 10^{-12}, G^{*}=4860, K=6\right)$

Table 1 Effect of the dimensionless load, rolling velocity, squeeze velocity, material parameter and ellipticity parameter on the dimensionless minimum film thickness

\begin{tabular}{|c|c|c|c|c|c|c|c|c|c|c|c|}
\hline Number & $W^{*}$ & $U^{*}$ & $K$ & $G^{*}$ & $\begin{array}{c}\frac{\mathrm{d} h}{\mathrm{~d} t} \\
(\mathrm{~m} / \mathrm{s})\end{array}$ & $S^{*}$ & $\bar{h}_{\min }$ & $\tilde{H}_{\min }$ & $\hat{H}_{\min }$ & $\begin{array}{c}\frac{\bar{h}_{\min }-\tilde{H}_{\min }}{\tilde{H}_{\min }} \\
(\%)\end{array}$ & $\begin{array}{c}\frac{\tilde{H}_{\min }-\hat{H}_{\min }}{\tilde{H}_{\min }} \\
(\%)\end{array}$ \\
\hline 1 & $0.7216 \mathrm{E}-6$ & $0.0842 \mathrm{E}-11$ & 6.00 & 4860 & -0.00000 & -0.00000 & $3.90 \mathrm{E}-6$ & $3.88 \mathrm{E}-06$ & $3.95 \mathrm{E}-06$ & 0.52 & 1.65 \\
\hline 2 & $0.7216 \mathrm{E}-6$ & $0.1683 \mathrm{E}-11$ & 6.00 & 4860 & -0.00000 & -0.00000 & $6.25 \mathrm{E}-6$ & $6.13 \mathrm{E}-06$ & $6.32 \mathrm{E}-06$ & 1.96 & 3.21 \\
\hline 3 & $0.7216 \mathrm{E}-6$ & $0.2524 \mathrm{E}-11$ & 6.00 & 4860 & -0.00000 & -0.00000 & $8.25 \mathrm{E}-6$ & $8.00 \mathrm{E}-06$ & $8.33 \mathrm{E}-06$ & 3.13 & 4.14 \\
\hline 4 & $0.7216 \mathrm{E}-6$ & $0.3365 \mathrm{E}-11$ & 6.00 & 4860 & -0.00000 & -0.00000 & $9.96 \mathrm{E}-6$ & $9.67 \mathrm{E}-06$ & $1.01 \mathrm{E}-05$ & 3.00 & 4.80 \\
\hline 5 & $0.7216 \mathrm{E}-6$ & $0.4208 \mathrm{E}-11$ & 6.00 & 4860 & -0.00000 & -0.00000 & $1.13 \mathrm{E}-5$ & $1.12 \mathrm{E}-05$ & $1.18 \mathrm{E}-05$ & 0.89 & 5.32 \\
\hline 6 & $0.7216 \mathrm{E}-6$ & $0.5889 \mathrm{E}-11$ & 6.00 & 4860 & -0.00000 & -0.00000 & $1.45 \mathrm{E}-5$ & $1.34 \mathrm{E}-05$ & $1.48 \mathrm{E}-05$ & 8.21 & 6.10 \\
\hline 7 & $0.7216 \mathrm{E}-6$ & $0.8414 \mathrm{E}-11$ & 6.00 & 4860 & -0.00000 & -0.00000 & $1.83 \mathrm{E}-5$ & $1.77 \mathrm{E}-05$ & $1.89 \mathrm{E}-05$ & 3.39 & 6.93 \\
\hline 8 & $0.7216 \mathrm{E}-6$ & $0.1263 \mathrm{E}-10$ & 6.00 & 4860 & -0.00000 & -0.00000 & $2.40 \mathrm{E}-5$ & 2.31E-05 & 2.49E-05 & 3.90 & 7.89 \\
\hline 9 & $0.7216 \mathrm{E}-6$ & $0.1683 \mathrm{E}-10$ & 6.00 & 4860 & -0.00000 & -0.00000 & $2.90 \mathrm{E}-5$ & 2.79E-05 & 3.03E-05 & 3.94 & 8.58 \\
\hline 10 & $0.7216 \mathrm{E}-6$ & $0.2525 \mathrm{E}-10$ & 6.00 & 4860 & -0.00000 & -0.00000 & $3.75 \mathrm{E}-5$ & $3.64 \mathrm{E}-05$ & $3.99 \mathrm{E}-05$ & 3.02 & 9.55 \\
\hline 11 & $0.7216 \mathrm{E}-6$ & $0.2946 \mathrm{E}-10$ & 6.00 & 4860 & -0.00000 & -0.00000 & $4.13 \mathrm{E}-5$ & 4.03E-05 & 4.43E-05 & 2.48 & 9.92 \\
\hline 12 & $0.7216 \mathrm{E}-6$ & $0.3367 \mathrm{E}-10$ & 6.00 & 4860 & -0.00000 & -0.00000 & $4.50 \mathrm{E}-5$ & 4.40E-05 & $4.85 \mathrm{E}-05$ & 2.27 & 10.25 \\
\hline 13 & $0.7216 \mathrm{E}-6$ & $0.4208 \mathrm{E}-10$ & 6.00 & 4860 & -0.00000 & -0.00000 & $5.14 \mathrm{E}-5$ & $5.10 \mathrm{E}-05$ & $5.65 \mathrm{E}-05$ & 0.78 & 10.79 \\
\hline 14 & $0.7216 \mathrm{E}-6$ & $0.5048 \mathrm{E}-10$ & 6.00 & 4860 & -0.00000 & -0.00000 & $5.75 \mathrm{E}-5$ & $5.74 \mathrm{E}-05$ & $6.39 \mathrm{E}-05$ & 0.17 & 11.23 \\
\hline 15 & $0.7216 \mathrm{E}-6$ & $0.3365 \mathrm{E}-11$ & 6.00 & 2430 & -0.00000 & -0.00000 & $6.93 \mathrm{E}-6$ & $6.95 \mathrm{E}-06$ & $7.21 \mathrm{E}-06$ & 0.29 & 3.79 \\
\hline 16 & $0.4567 \mathrm{E}-6$ & $0.2130 \mathrm{E}-11$ & 6.00 & 3840 & -0.00000 & -0.00000 & $6.53 \mathrm{E}-6$ & $6.58 \mathrm{E}-06$ & $6.84 \mathrm{E}-06$ & 0.76 & 3.93 \\
\hline 17 & $0.3685 \mathrm{E}-6$ & $0.1682 \mathrm{E}-11$ & 6.00 & 4860 & -0.00000 & -0.00000 & $6.36 \mathrm{E}-6$ & $6.39 \mathrm{E}-06$ & 6.64E-06 & 0.47 & 3.98 \\
\hline 18 & $0.2947 \mathrm{E}-6$ & $0.1346 \mathrm{E}-11$ & 6.00 & 6075 & -0.00000 & -0.00000 & $6.25 \mathrm{E}-6$ & $6.22 \mathrm{E}-06$ & $6.47 \mathrm{E}-06$ & 0.48 & 4.05 \\
\hline 19 & $0.2456 \mathrm{E}-6$ & $0.1122 \mathrm{E}-6$ & 6.00 & 7290 & -0.00000 & -0.00000 & $6.15 \mathrm{E}-6$ & $6.08 \mathrm{E}-06$ & $6.33 \mathrm{E}-06$ & 1.15 & 4.10 \\
\hline 20 & $0.3685 \mathrm{E}-6$ & $0.1682 \mathrm{E}-11$ & 6.00 & 4860 & -0.00000 & -0.00000 & $6.36 \mathrm{E}-6$ & $6.39 \mathrm{E}-06$ & $6.64 \mathrm{E}-06$ & 0.47 & 3.98 \\
\hline 21 & $0.3685 \mathrm{E}-6$ & $0.1682 \mathrm{E}-11$ & 6.00 & 4860 & $-2.50 \mathrm{E}-6$ & $-4.21 \mathrm{E}-17$ & 7.31E-6 & $6.91 \mathrm{E}-06$ & - & 5.79 & - \\
\hline 22 & $0.3685 \mathrm{E}-6$ & $0.1682 \mathrm{E}-11$ & 6.00 & 4860 & $-5.00 \mathrm{E}-6$ & $-8.41 \mathrm{E}-17$ & 7.92E-6 & 7.43E-06 & - & 6.59 & - \\
\hline 23 & $0.3685 \mathrm{E}-6$ & $0.1682 \mathrm{E}-11$ & 6.00 & 4860 & $-1.00 \mathrm{E}-5$ & $-1.68 \mathrm{E}-16$ & $9.05 \mathrm{E}-6$ & $8.47 \mathrm{E}-06$ & - & 6.85 & - \\
\hline 24 & $0.3685 \mathrm{E}-6$ & $0.1682 \mathrm{E}-11$ & 6.00 & 4860 & $-1.25 \mathrm{E}-5$ & $-2.10 \mathrm{E}-16$ & $9.59 \mathrm{E}-6$ & $8.99 \mathrm{E}-06$ & - & 6.67 & - \\
\hline 25 & $0.3685 \mathrm{E}-6$ & $0.1682 \mathrm{E}-11$ & 6.00 & 4860 & $-1.50 \mathrm{E}-5$ & $-2.52 \mathrm{E}-16$ & $1.01 \mathrm{E}-5$ & $9.52 \mathrm{E}-06$ & - & 6.09 & - \\
\hline 26 & $0.3685 \mathrm{E}-6$ & $0.1682 \mathrm{E}-11$ & 6.00 & 4860 & $-3.00 \mathrm{E}-5$ & $-5.05 \mathrm{E}-16$ & $1.29 \mathrm{E}-5$ & $1.26 \mathrm{E}-05$ & - & 2.38 & - \\
\hline 27 & $0.3685 \mathrm{E}-6$ & $0.1682 \mathrm{E}-11$ & 6.00 & 4860 & $-3.50 \mathrm{E}-5$ & $-5.89 \mathrm{E}-16$ & $1.36 \mathrm{E}-5$ & $1.37 \mathrm{E}-05$ & - & 0.73 & - \\
\hline 28 & $0.3685 \mathrm{E}-6$ & $0.1682 \mathrm{E}-11$ & 6.00 & 4860 & $-5.00 \mathrm{E}-5$ & $-8.41 \mathrm{E}-16$ & $1.57 \mathrm{E}-5$ & $1.68 \mathrm{E}-05$ & - & 6.55 & - \\
\hline 29 & $0.3685 \mathrm{E}-7$ & $0.1682 \mathrm{E}-11$ & 6.00 & 4860 & -0.00000 & -0.00000 & 7.23E-6 & 7.37E-06 & 7.86E-06 & 1.90 & 6.65 \\
\hline 30 & $0.1105 \mathrm{E}-6$ & $0.1682 \mathrm{E}-11$ & 6.00 & 4860 & -0.00000 & -0.00000 & $6.89 \mathrm{E}-6$ & $6.88 \mathrm{E}-06$ & $7.25 \mathrm{E}-06$ & 0.15 & 5.37 \\
\hline 31 & $0.2210 \mathrm{E}-6$ & $0.1682 \mathrm{E}-11$ & 6.00 & 4860 & -0.00000 & -0.00000 & $6.59 \mathrm{E}-6$ & $6.59 \mathrm{E}-06$ & $6.89 \mathrm{E}-06$ & 0.00 & 4.57 \\
\hline 32 & $0.2487 \mathrm{E}-6$ & $0.1682 \mathrm{E}-11$ & 6.00 & 4860 & -0.00000 & -0.00000 & $6.56 \mathrm{E}-6$ & $6.54 \mathrm{E}-06$ & $6.83 \mathrm{E}-06$ & 0.31 & 4.43 \\
\hline 33 & $0.2578 \mathrm{E}-6$ & $0.1682 \mathrm{E}-11$ & 6.00 & 4860 & -0.00000 & -0.00000 & $6.56 \mathrm{E}-6$ & $6.53 \mathrm{E}-06$ & $6.82 \mathrm{E}-06$ & 0.46 & 4.39 \\
\hline 34 & $0.2763 \mathrm{E}-6$ & $0.1682 \mathrm{E}-11$ & 6.00 & 4860 & -0.00000 & -0.00000 & $6.51 \mathrm{E}-6$ & $6.50 \mathrm{E}-06$ & $6.78 \mathrm{E}-06$ & 0.15 & 4.31 \\
\hline 35 & $0.2947 \mathrm{E}-6$ & $0.1682 \mathrm{E}-11$ & 6.00 & 4860 & -0.00000 & -0.00000 & $6.47 \mathrm{E}-6$ & $6.47 \mathrm{E}-06$ & $6.75 \mathrm{E}-06$ & 0.00 & 4.23 \\
\hline 36 & $0.3685 \mathrm{E}-6$ & $0.1682 \mathrm{E}-11$ & 6.00 & 4860 & -0.00000 & -0.00000 & $6.36 \mathrm{E}-6$ & $6.39 \mathrm{E}-06$ & $6.64 \mathrm{E}-06$ & 0.47 & $\begin{array}{c}3.98 \\
\text { atinued over })\end{array}$ \\
\hline
\end{tabular}


Table 1 (continued)

\begin{tabular}{|c|c|c|c|c|c|c|c|c|c|c|c|}
\hline Number & $W^{*}$ & $U^{*}$ & $K$ & $G^{*}$ & $\begin{array}{c}\frac{\mathrm{d} h}{\mathrm{~d} t} \\
(\mathrm{~m} / \mathrm{s})\end{array}$ & $S^{*}$ & $\bar{h}_{\min }$ & $\tilde{H}_{\min }$ & $\hat{H}_{\min }$ & $\frac{\bar{h}_{\min }-\tilde{H}_{\min }}{\tilde{H}_{\min }}$ & $\frac{\tilde{H}_{\min }-\hat{H}_{\min }}{\tilde{H}_{\min }}\left(\begin{array}{c}\%)\end{array}\right.$ \\
\hline 37 & $0.4605 \mathrm{E}-6$ & $0.1682 \mathrm{E}-11$ & 6.00 & 4860 & -0.00000 & -0.00000 & $6.21 \mathrm{E}-6$ & $6.30 \mathrm{E}-06$ & $6.53 \mathrm{E}-06$ & 1.43 & 3.72 \\
\hline 38 & $0.5526 \mathrm{E}-6$ & $0.1682 \mathrm{E}-11$ & 6.00 & 4860 & -0.00000 & -0.00000 & $6.19 \mathrm{E}-6$ & $6.23 \mathrm{E}-06$ & $6.45 \mathrm{E}-06$ & 0.64 & 3.52 \\
\hline 39 & $0.6447 \mathrm{E}-6$ & $0.1682 \mathrm{E}-11$ & 6.00 & 4860 & -0.00000 & -0.00000 & $6.11 \mathrm{E}-6$ & $6.17 \mathrm{E}-06$ & $6.37 \mathrm{E}-06$ & 0.97 & 3.34 \\
\hline 40 & $0.7216 \mathrm{E}-6$ & $0.1683 \mathrm{E}-11$ & 6.00 & 4860 & -0.00000 & -0.00000 & $6.06 \mathrm{E}-6$ & $6.13 \mathrm{E}-06$ & $6.32 \mathrm{E}-06$ & 1.14 & 3.21 \\
\hline 41 & $0.9211 \mathrm{E}-6$ & $0.1682 \mathrm{E}-11$ & 6.00 & 4860 & -0.00000 & -0.00000 & 5.97E-6 & $6.03 \mathrm{E}-06$ & $6.21 \mathrm{E}-06$ & 1.00 & 2.94 \\
\hline 42 & $0.1105 \mathrm{E}-6$ & $0.1682 \mathrm{E}-11$ & 1.25 & 4860 & -0.00000 & -0.00000 & $3.85 \mathrm{E}-6$ & $3.99 \mathrm{E}-06$ & 4.22E-06 & 3.51 & 5.81 \\
\hline 43 & $0.1105 \mathrm{E}-6$ & $0.1682 \mathrm{E}-11$ & 1.50 & 4860 & -0.00000 & -0.00000 & $4.35 \mathrm{E}-6$ & $4.46 \mathrm{E}-06$ & $4.72 \mathrm{E}-06$ & 2.47 & 5.76 \\
\hline 44 & $0.1105 \mathrm{E}-6$ & $0.1682 \mathrm{E}-11$ & 1.75 & 4860 & -0.00000 & -0.00000 & $4.80 \mathrm{E}-6$ & $4.85 \mathrm{E}-06$ & $5.13 \mathrm{E}-06$ & 1.03 & 5.72 \\
\hline 45 & $0.1105 \mathrm{E}-6$ & $0.1682 \mathrm{E}-11$ & 2.00 & 4860 & -0.00000 & -0.00000 & $5.13 \mathrm{E}-6$ & $5.19 \mathrm{E}-06$ & $5.48 \mathrm{E}-06$ & 1.16 & 5.68 \\
\hline 46 & $0.1105 \mathrm{E}-6$ & $0.1682 \mathrm{E}-11$ & 2.50 & 4860 & -0.00000 & -0.00000 & $5.72 \mathrm{E}-6$ & $5.71 \mathrm{E}-06$ & $6.03 \mathrm{E}-06$ & 0.18 & 5.61 \\
\hline 47 & $0.1105 \mathrm{E}-6$ & $0.1682 \mathrm{E}-11$ & 3.00 & 4860 & -0.00000 & -0.00000 & $6.12 \mathrm{E}-6$ & $6.08 \mathrm{E}-06$ & $6.42 \mathrm{E}-06$ & 0.66 & 5.55 \\
\hline 48 & $0.1105 \mathrm{E}-6$ & $0.1682 \mathrm{E}-11$ & 4.00 & 4860 & -0.00000 & -0.00000 & $6.60 \mathrm{E}-6$ & $6.53 \mathrm{E}-06$ & $6.89 \mathrm{E}-06$ & 1.07 & 5.46 \\
\hline 49 & $0.1105 \mathrm{E}-6$ & $0.1682 \mathrm{E}-11$ & 6.00 & 4860 & -0.00000 & -0.00000 & $6.89 \mathrm{E}-6$ & $6.88 \mathrm{E}-06$ & $7.25 \mathrm{E}-06$ & 0.15 & 5.37 \\
\hline 50 & $0.1105 \mathrm{E}-6$ & $0.1682 \mathrm{E}-11$ & 8.00 & 4860 & -0.00000 & -0.00000 & $7.06 \mathrm{E}-6$ & $6.97 \mathrm{E}-06$ & 7.34E-06 & 1.29 & 5.33 \\
\hline 51 & $0.1105 \mathrm{E}-6$ & $0.1682 \mathrm{E}-11$ & 1.25 & 4860 & $-1.00 \mathrm{E}-5$ & $-1.68 \mathrm{E}-16$ & $6.69 \mathrm{E}-6$ & $5.47 \mathrm{E}-06$ & - & 22.30 & - \\
\hline 52 & $0.1105 \mathrm{E}-6$ & $0.1682 \mathrm{E}-11$ & 1.50 & 4860 & $-1.00 \mathrm{E}-5$ & $-1.68 \mathrm{E}-16$ & $7.21 \mathrm{E}-6$ & $6.11 \mathrm{E}-06$ & - & 18.00 & - \\
\hline 53 & $0.1105 \mathrm{E}-6$ & $0.1682 \mathrm{E}-11$ & 1.75 & 4860 & $-1.00 \mathrm{E}-5$ & $-1.68 \mathrm{E}-16$ & $7.63 \mathrm{E}-6$ & $6.66 \mathrm{E}-06$ & - & 14.56 & - \\
\hline 54 & $0.1105 \mathrm{E}-6$ & $0.1682 \mathrm{E}-11$ & 2.00 & 4860 & $-1.00 \mathrm{E}-5$ & $-1.68 \mathrm{E}-16$ & $7.98 \mathrm{E}-6$ & 7.11E-06 & - & 12.24 & - \\
\hline 55 & $0.1105 \mathrm{E}-6$ & $0.1682 \mathrm{E}-11$ & 2.50 & 4860 & $-1.00 \mathrm{E}-5$ & $-1.68 \mathrm{E}-16$ & $8.35 \mathrm{E}-6$ & $7.83 \mathrm{E}-06$ & - & 6.64 & - \\
\hline 56 & $0.1105 \mathrm{E}-6$ & $0.1682 \mathrm{E}-11$ & 3.00 & 4860 & $-1.00 \mathrm{E}-5$ & $-1.68 \mathrm{E}-16$ & $8.57 \mathrm{E}-6$ & 8.34E-06 & - & 2.76 & - \\
\hline 57 & $0.1105 \mathrm{E}-6$ & $0.1682 \mathrm{E}-11$ & 4.00 & 4860 & $-1.00 \mathrm{E}-5$ & $-1.68 \mathrm{E}-16$ & $8.87 \mathrm{E}-6$ & $8.97 \mathrm{E}-06$ & - & 1.11 & - \\
\hline 58 & $0.1105 \mathrm{E}-6$ & $0.1682 \mathrm{E}-11$ & 6.00 & 4860 & $-1.00 \mathrm{E}-5$ & $-1.68 \mathrm{E}-16$ & $9.13 \mathrm{E}-6$ & $9.45 \mathrm{E}-06$ & - & 3.39 & - \\
\hline 59 & $0.1105 \mathrm{E}-6$ & $0.1682 \mathrm{E}-11$ & 8.00 & 4860 & $-1.00 \mathrm{E}-5$ & $-1.68 \mathrm{E}-16$ & $9.12 \mathrm{E}-6$ & $9.57 \mathrm{E}-06$ & - & 4.70 & - \\
\hline 60 & $0.7216 \mathrm{E}-7$ & $0.1682 \mathrm{E}-11$ & 6.00 & 4860 & $-1.00 \mathrm{E}-5$ & $-1.68 \mathrm{E}-16$ & $8.81 \mathrm{E}-6$ & $8.41 \mathrm{E}-06$ & - & 4.76 & - \\
\hline 61 & $0.7216 \mathrm{E}-7$ & $0.5889 \mathrm{E}-11$ & 6.00 & 4860 & $-1.00 \mathrm{E}-5$ & $-1.68 \mathrm{E}-16$ & $1.59 \mathrm{E}-5$ & $1.92 \mathrm{E}-05$ & - & 17.19 & - \\
\hline 62 & $0.7216 \mathrm{E}-7$ & $0.2525 \mathrm{E}-10$ & 6.00 & 4860 & $-1.00 \mathrm{E}-5$ & $-1.68 \mathrm{E}-16$ & $3.79 \mathrm{E}-5$ & 5E-05 & - & 24.20 & - \\
\hline 63 & $0.3685 \mathrm{E}-7$ & $0.1682 \mathrm{E}-11$ & 6.00 & 4860 & $-1.00 \mathrm{E}-5$ & $-1.68 \mathrm{E}-16$ & $9.06 \mathrm{E}-6$ & $1.01 \mathrm{E}-05$ & - & 10.30 & - \\
\hline 64 & $0.2210 \mathrm{E}-6$ & $0.1682 \mathrm{E}-11$ & 6.00 & 4860 & $-1.00 \mathrm{E}-5$ & $-1.68 \mathrm{E}-16$ & $9.23 \mathrm{E}-6$ & $9.05 \mathrm{E}-06$ & - & 1.99 & - \\
\hline 65 & $0.2578 \mathrm{E}-6$ & $0.1682 \mathrm{E}-11$ & 6.00 & 4860 & $-1.00 \mathrm{E}-5$ & $-1.68 \mathrm{E}-16$ & $9.29 \mathrm{E}-6$ & $8.96 \mathrm{E}-06$ & - & 3.68 & - \\
\hline 66 & $0.2947 \mathrm{E}-6$ & $0.1682 \mathrm{E}-11$ & 6.00 & 4860 & $-1.00 \mathrm{E}-5$ & $-1.68 \mathrm{E}-16$ & $9.24 \mathrm{E}-6$ & 8.89E-06 & - & 3.94 & - \\
\hline 67 & $0.4605 \mathrm{E}-6$ & $0.1682 \mathrm{E}-11$ & 6.00 & 4860 & $-1.00 \mathrm{E}-5$ & $-1.68 \mathrm{E}-16$ & $8.94 \mathrm{E}-6$ & $8.65 \mathrm{E}-06$ & - & 3.35 & - \\
\hline 68 & $0.9211 \mathrm{E}-6$ & $0.1682 \mathrm{E}-11$ & 6.00 & 4860 & $-1.00 \mathrm{E}-5$ & $-1.68 \mathrm{E}-16$ & $8.84 \mathrm{E}-6$ & $8.28 \mathrm{E}-06$ & - & 6.76 & - \\
\hline 70 & $0.7216 \mathrm{E}-7$ & $0.1682 \mathrm{E}-11$ & 6.00 & 4860 & $-1.00 \mathrm{E}-5$ & $-1.68 \mathrm{E}-16$ & $1.03 \mathrm{E}-5$ & $9.54 \mathrm{E}-06$ & - & 7.97 & - \\
\hline 71 & $0.2487 \mathrm{E}-6$ & $0.1682 \mathrm{E}-11$ & 6.00 & 4860 & $-1.00 \mathrm{E}-5$ & $-1.68 \mathrm{E}-16$ & $8.62 \mathrm{E}-6$ & $8.36 \mathrm{E}-06$ & - & 3.11 & - \\
\hline 72 & $0.2947 \mathrm{E}-6$ & $0.1682 \mathrm{E}-11$ & 6.00 & 4860 & $-1.00 \mathrm{E}-5$ & $-1.68 \mathrm{E}-16$ & $8.79 \mathrm{E}-6$ & 8.54E-06 & - & 2.93 & - \\
\hline
\end{tabular}

\section{ACKNOWLEDGEMENTS}

The authors would like to express their gratitude to the Iranian Ministry of Culture and Higher Education and the Sahand University of Technology for sponsoring this research project.

\section{REFERENCES}

1 Grubin, A. N. Investigation of Scientific and Industrial Research, Book 30, 1949 (Central Scientific Research Institute for Technology and Mechanical Engineering, Moscow).

2 Cameron, A. and Gohar, R. Theoretical and experimental studies of the oil film in lubricated point contacts. Proc. $R$. Soc. A, 1966, 291, 520-536.

3 Bahadoran, H. and Gohar, R. End closure in EHL line contact. J. Mech. Engng Sci., 1974, 16, 264-270.

4 Safa, M. M., Anderson, J. C. and Leather, J. A. Transducers for pressure, temperature and oil film thickness measurement in bearings. Sensors Actuators, 1982-3, 3, 119-128.

5 Dowson, D. and Higginson, G. R. A numerical solution to the elastohydrodynamic problem. J. Mech. Engng Sci., 1959, 1, $6-15$.

6 Ranger, A. P., Ettles, C. M. M. and Cameron, A. The solution of point contact EHL problem. Proc. R. Soc. Lond. A, 1975, 346, 227-244.

7 Evans, H. P. and Snidle, R. W. The elastohydrodynamic lubrication of point contacts at heavy loads. Proc. R. Soc. Lond. A, 1982, 382, 183-199.

8 Snidle, R. W. and Archard, J. F. Lubrication of elliptical contacts. Proc. Instn Mech. Engrs, 1968-9, 183(3B).

9 Archard, J. F. and Kirk, M. T. Lubrication at point contacts. Proc. R. Soc. A, 1961, 261, 532-550.

10 Hamilton, G. M. and Moore, S. L. Deformation and pressure in an elastohydrodynamic contact. Proc. R. Soc. Lond. A. 1971, 322, 313-330.

11 Houpert, L., Ioannides, E., Kuypers, J. C. and Tripp, J. The effect of the EHD pressure spike on rolling bearing fatigue. Trans. ASME, J. Tribology, 1987, 109, 444-451. 
12 Czyzewski, T. Changes in the stress field in the elastohydrodynamic contact zone due to some operating factors and their role in the rolling contact fatigue of cylindrical surfaces. Wear, 1975, 31, 119-140.

13 Christensen, H. The oil film in a closing gap. Proc. R. Soc. Lond. A, March 1962, 266 (1326), 312-328.

14 Christensen, H. Elastohydrodynamic theory of spherical bodies in normal approach. Trans. ASME, J. Lubric. Techol., January 1970, 92(1), 145-154.

15 Herrebrugh, K. Elastohydrodynamic squeeze between two cylinders in normal approach. Trans. ASME, J. Lubric. Technol., April 1970, 92(2), 292-302.

16 Dowson, D. and Jones, D. An optical-interference method of measurement of time-dependent elastohydrodynamic film profiles. Report 3, Symposium on Experimental Methods in Tribology, Proc. Instn Mech. Engrs, 1967-8, 182(3G), 49-52.

17 Paul, G. R. and Cameron, A. Absolute optical measurement of the oil entrapment in a dropping ball. Proc. Instn Mech. Engrs, 1972, 95, 69-74.

18 Safa, M. and Gohar, R. Pressure distribution under a ball impacting a thin lubricant layer. Trans. ASME, J. Lubric. Technol., 1986, 108(3), 372-376.

19 Bedewi, M. A. A., Dowson, D. and Taylor, C. M. The squeeze-film lubrication of ellipsoids. J. Phys. D: Appl. Phys., 1992, 25, A133-A140.

20 Lee, R. and Hamrock, B. J. Squeeze and entraining motion in nonconformal line contacts. Part II: hydrodynamic lubrication. Trans. ASME, J. Lubric. Technol., January 1989, 111, 8-16.

21 Mostofi, A. and Gohar, R. Oil film thickness and pressure distribution in elastohydrodynamic point contacts. Trans. ASME, J. Lubric. Technol., April 1982, 24(4), 173-182.

22 Rahnejat, H. Influence of vibration on the oil film in concentrated contacts. PhD thesis, Imperial College of Science and Technology, 1984.

23 Dowson, D. and Wang, D. An analysis of the normal bouncing of a solid elastic ball on a oily plate. Wear, 1994, 179(1-2), 29-37.

24 Wijnant, Y. H. and Venner, C. H. Analysis of an EHL circular contact incorporating rolling element vibration. In Proceedings of the 23rd Leeds-Lyon Symposium on Tribology, September 1996, pp. 445-456 (Elsevier, Amsterdam).

25 Dowson, D., Ruddy, B. and Economou, P. The elastohydrodynamic lubrication of piston rings. Proc. R. Soc. Lond. A, 1983, 386, 409-430.

26 Matthews, J. and Sadeghi, F. Kinematics and lubrication of camshaft roller follower mechanisms. J. Tribology Trans., 1996, 39(2), 425-433.

27 Dowson, D., Taylor, C. and Zhu, G. A transient elastohydrodynamic lubrication analysis of a cam and follower. J. Phys. D: Appl. Phys., 1992, 125(1A), A313-A320.

28 Mei, X. and Xie, Y. A numerical-analysis of the nonsteady EHL process in high-speed rotating engine cam/tappet pairs. Trans. ASME, J. Tribology, 1996, 118(3), 637-643.

29 Mehdigholi, H., Rahnejat, H. and Gohar, R. Vibration response of wavy surfaced disc in elastohydrodynamic rolling contact. Wear, 1990, 139, 1-15.

30 Dareing, D. W. and Johnson, K. L. Fluid film damping of rolling contact vibrations. J. Mech. Engng Sci., 1975.

31 Roelands, C. J. A. Correlation aspects of viscosity-temperature-pressure relationship of lubricating oils. PhD thesis, Delft University of Technology, The Netherlands, 1966.

32 Hamrock, B. J. and Dowson, D. Isothermal elastohydrody- namic lubrication of point contacts. Part I: theoretical formulation. Trans. ASME, J. Lubric. Technol., April 1976, 98, $223-$ 229.

33 Hamrock, B. J. and Dowson, D. Isothermal elastohydrodynamic lubrication of point contacts. Part II: ellipticity parameter results. Trans. ASME, J. Lubric. Technol., July 1976, 98, 375-383.

34 Hamrock, B. J. and Dowson, D. Isothermal elastohydrodynamic lubrication of point contacts. Part III: fully flooded results. Trans. ASME, J. Lubric. Technol., April 1977, 99, 264-276.

35 Hamrock, B. J. and Dowson, D. Isothermal elastohydrodynamic lubrication of point contacts. Part IV: starvation results. Trans. ASME, J. Lubric. Technol., January 1977, 99, 15-23.

36 Johnson, K. L. Contact Mechanics, 1987 (Cambridge University Press, Cambridge).

37 Johns-Rahnejat, P. M. and Gohar, R. Point contact elastohydrodynamic pressure distribution and sub-surface stress field. In Proceedings of the First International Symposium on MultiBody Dynamics, March 1997, pp. 161-177 (Mechanical Engineering Publications, London).

38 Chittenden, R. J., Dowson, D., Dunn, J. F. and Taylor, C. M. A theoretical analysis of the isothermal elastohydrodynamic lubrication of concentrated contacts. Proc. R. Soc. Lond. A, 1985, 397, 271-294.

39 Greenwood, J. A. Film thickness in circular elastohydrodynamic contacts. Proc. Instn Mech. Engrs, Part C, Journal of Mechanical Engineering Science, 1988, 202(C1), 11-17.

40 Hamilton, G. M. The hydrodynamic of cam follower. Tribology Int., June 1980, 113-119.

\section{APPENDIX}

$$
\begin{aligned}
& A_{i, j}=3 \mu_{i+1, j}+\mu_{i-1, j} \\
& B_{i, j}=\left(\frac{\bar{c}}{\bar{d} K}\right)^{2}\left(\mu_{i, j+1}+3 \mu_{i, j-1}\right) \\
& C_{i, j}=\mu_{i+1, j}+3 \mu_{i-1, j} \\
& N_{i, j}=\left(\frac{\bar{c}}{\bar{d} K}\right)^{2}\left(3 \mu_{i, j+1}+\mu_{i, j-1}\right) \\
& M_{i, j}=\frac{24 U^{*} b}{\bar{d} R_{x} \bar{h}_{i, j}^{1.5}}\left(\bar{\rho}_{i+1, j} \bar{h}_{i+1, j}-\bar{\rho}_{i-1, j} \bar{h}_{i-1, j}\right) \\
& +\frac{24 \bar{\rho}_{i, j} b^{2} \eta_{0}}{\bar{d} R_{x}^{3} \bar{h}_{i, j}^{1.5} E^{\prime}}\left(\frac{\mathrm{d} h}{\mathrm{~d} t}\right) \\
& L_{i, j}=4\left(\mu_{i, j+1}+\mu_{i, j-1}\right)+4\left(\frac{\bar{c}}{\bar{d} K}\right)^{2}\left(\mu_{i, j+1}+\mu_{i, j-1}\right) \\
& +\left[\left(\frac{3}{2 \bar{h}_{i, j}^{1.5}}\right) \mu_{i+1, j} \bar{h}_{i+1, j}^{0.5}\left(3 \bar{h}_{i+1, j}-4 \bar{h}_{i, j}+\bar{h}_{i-1, j}\right)\right] \\
& +\mu_{i-1, j} \bar{h}_{i-1, j}^{0.5}\left(\bar{h}_{i+1, j}-4 \bar{h}_{i, j}+3 \bar{h}_{i-1, j}\right) \\
& +\left(\frac{\bar{c}}{\bar{d} K}\right)^{2}\left[\mu_{i, j+1} \bar{h}_{i, j+1}^{0.5}\left(3 \bar{h}_{i, j+1}-4 \bar{h}_{i, j}+\bar{h}_{i, j-1}\right)\right. \\
& \left.+\mu_{i, j-1} H_{i, j-1}^{0.5}\left(\bar{h}_{i, j+1}-4 \bar{h}_{i, j}+3 \bar{h}_{i, j-1}\right)\right]
\end{aligned}
$$

